Geografia e Ordenamento do Território, Revista Eletrónica

Centro de Estudos de Geografia e Ordenamento do Território

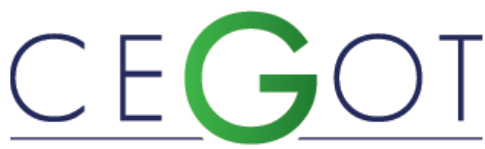

Centro de Estudos de Geografia

e Ordenamento do Território http://cegot.org/ojs/got

ISSN : 2182-1267

Diogo, $\mathrm{H}$.

CEGOT

helderdiogo@sapo.pt

\title{
Territórios e paisagens culturais na emigração lusa
}

Referência: Diogo, H. (2012). Territórios e paisagens culturais na emigração lusa. Revista de Geografia e Ordenamento do Território, n. 1 (Junho). Centro de Estudos de Geografia e Ordenamento do Território. Pág. 41 a 58.

\section{Resumo}

A emigração portuguesa e a constituição de comunidades lusas nos cinco continentes refletem processos de construção territorial diversificados. Partindo do exemplo de implantação de duas comunidades, uma em solo americano na região de Toronto no Canadá e outra em solo europeu em várias regiões de França, embora com principal destaque para a região de Lyon, procuramos analisar o processo de fixação destas comunidades nos respetivos territórios de acolhimento. O desenvolvimento de inúmeras atividades étnicas de todo o tipo com base numa matriz cultural lusa comum permitiu a construção de paisagens culturais diversificadas e diferenciadas nas sociedades de acolhimento. 
Palavras-Chave: Emigração, território, territorialidade, paisagem cultural, étnico.

\section{Abstract}

The Portuguese emigration and the building of Portuguese communities in the five continents reflect diversified processes of territorial construction. Starting from the example of the implantation of two communities, one in American soil in the region of Toronto, Canada, and the other in European soil in various regions of France, though highlighting the region of Lyon, we tried to analyse the setting process of these communities in the respective host territories. Among various conclusions, we draw attention to the fact that the development of ethnic activities based upon a common Portuguese cultural identity has been allowing the making of diverse and distinct cultural landscapes in the host societies.

Keywords: Emigration, territory, territoriality, cultural landscape, ethnic. 


\section{Introdução}

Os territórios e as regiões nas suas mais diversas escalas encontram-se influenciados pelos fenómenos migratórios.

A Geografia investiga os fenómenos migratórios a partir de uma série de variáveis ao nível económico, político, cultural ou social que, com o passar do tempo, se vão transformando e cruzando. Os fenómenos migratórios implicam por definição movimentos, e a Geografia permite analisar a mobilidade de populações, os territórios, as trocas permanentes e, não menos importante a (re)construção de territórios e paisagens culturais e a produção de espaços.

A cultura que herdamos do passado, enriquecida por tudo o que o presente lhe traz, dá sentido à existência coletiva e individual do ser humano, permitindo a organização das sociedades e do território.

O geógrafo Joel Bonnemaison (2000) define a cultura como algo que se transmite e que se reinventa em permanência. Os homens vivem a cultura num dado momento e num determinado espaço. Assim sendo, podemos conceber que os imigrantes formam comunidades com cultura(s) e território(s) próprios que evoluem e se reinventam.

Para Guy di Méo (1998), o território significa ter em conta um lugar de todos os registos da vida humana e social. Ao conceito de território, o autor também associa os conceitos de identidade e de memória, sendo que o mesmo toma o sentido daqueles que se apropriam dele.

Paul Claval (1995), mentor da Geografia Cultural em França, refere que só é possível definir um grupo e pertença quando no espaço são combinados a língua, a moral, a religião e os costumes. As pessoas modelam esses lugares pela sua ação e presença. Paralelamente, o ambiente que aí encontram e as pessoas que eles conhecem influem sobre as suas ideias, a sua sensibilidade e a sua conceção da vida (Claval, 2008:15).

Os territórios da imigração são simultaneamente funcionais e altamente simbólicos. Os imigrantes movem-se assim em contexto de multi-territorialidade. Trata se de uma multi-territorialidade vivida em vários espaços providos de uma essência cultural própria que contribuem para uma afirmação identitária individual e colectiva. 
Nos territórios da imigração, as atividades étnicas (comércio, restauração, fenómeno associativo, entre outros) constituem bons exemplos de apropriação e construção de espaços que carregam um forte significado cultural e identitário.

Dufoix (2000:82) considera que a concentração de imigrantes numa mesma cidade favorece o processo de (re)constituição identitária entre pares. Segundo o autor, o local torna-se então o lugar de produção de identidades comunitárias baseadas no modelo do país de origem. Toda esta construção identitária apoia-se em instituições ou práticas que asseguram a sua continuidade na área de acolhimento numa perspetiva transgeracional.

Com base nos poucos estudos teóricos e empíricos da Geografia nesta temática, optámos por traçar alguns processos de implantação territorial e de desenvolvimento de paisagens culturais na emigração portuguesa em duas regiões do globo particularmente estudadas por geógrafos. A primeira concerne a América do Norte, nomeadamente a região de Toronto no Canadá, que regista uma das principais comunidades lusas neste continente, e a segunda na Europa, o principal destino da imigração lusa que é a França ${ }^{1}$, particularmente na região de Lyon onde encontramos a segunda maior comunidade portuguesa neste país. À semelhança de muitos outros exemplos de implantação da comunidade lusa noutros pontos do globo que se fixaram após a segunda guerra mundial, ambas as comunidades apresentam características comuns mas também manifestam diferenças em termos de processos de fixação e de desenvolvimento de paisagens culturais nos respetivos territórios de acolhimento.

\subsection{Dos territórios às territorialidades na emigração portuguesa}

O geógrafo Rogério Haesbaert (2004:3) considera que a noção de territorialidade é mais ampla do que a de território: a todo o território corresponde uma territorialidade, mas nem toda a territorialidade implica a existência de um território, já que o território necessita de uma base material, concreta, enquanto que a territorialidade pode ser a dimensão simbólica, um referencial territorial (simbólico)

\footnotetext{
${ }^{1}$ Segundo o INSEE (2008), em França, a comunidade portuguesa com 580598 efetivos (apenas indivíduos naturais de Portugal; este número não contempla os que adquiriram a nacionalidade francesa ou que têm a dupla nacionalidade) é a terceira comunidade estrangeira mais importante no país depois da argelina e da marroquina. Em 2011, os serviços consulares portugueses registam um stock de cerca de 1124185 portugueses neste país (Direcção-Geral dos Assuntos Consulares e Comunidades Portuguesas - DGACCP).
} 
para a construção de um território que não exige obrigatoriamente uma forma concreta (suporte espacial).

Para o geógrafo Robert Sack (1986:5), a territorialidade nos humanos é uma estratégia geográfica determinante que permite controlar gentes e coisas numa área específica. Territórios políticos e propriedades privadas ocorrem em graus variados em diversos contextos sociais.

A territorialidade, além de incorporar uma dimensão política, diz também respeito às relações económicas e culturais, pois está intimamente ligada ao modo como os indivíduos utilizam o espaço, se organizam nele e ao significado que lhe atribuem.

Em contexto imigratório português em França, Albano Cordeiro (1999:3) evoca a criação de um terceiro território que se situa algures entre a sociedade local francesa e a aldeia de origem. Trata-se de um espaço eminentemente económico, social mas também cultural, já que prolonga as ligações estabelecidas entre as famílias, ao criar espaços associativos próprios, ao prestar apoio na procura de um emprego e ao apoiar nas diferentes tarefas relacionadas com a educação dos filhos. Do ponto vista cultural, trata-se eminentemente de um território com grande vocação para o lazer e o divertimento.

A territorialidade em contexto migratório reenvia-nos, de facto, para o estudo da implantação territorial dos imigrantes nas áreas de chegada, das suas condições de habitação, dos espaços económicos, sociais, culturais e étnicos que frequentam e que permitem criar e manter uma identidade cultural própria. É importante destacar que os territórios da emigração são simultaneamente funcionais e altamente simbólicos. 0 processo de globalização e uma maior mobilidade geográfica a ele associado permite vivências multiterritoriais reais e simbólicas.

Na América do norte e principalmente no Canadá, Pierre George (1976:138) a propósito da implantação territorial dos portugueses, referira o seguinte:

em 1970, Toronto registava aproximadamente 70000 portugueses. A comunidade judaica, a mais velha comunidade estrangeira local que ocupou em primeiro uma parte do centro da cidade na zona do actual edifício da câmara municipal e da cidade chinesa, transferiu-se depois para Kensington Market. Ela emigrou depois nos anos 
1930 seguindo um processo de promoção económica e social para um bairro mais confortável, Forest Hill Village, abandonando assim o antigo bairro da sinagoga à volta de Kensington Market aos mediterrânicos e em particular aos portugueses. Estes reocuparam o antigo bairro judaico. Em cada caso, lojas, letreiros, posters, lembram a tonalidade dominante do povo do bairro. O ambiente é o mesmo que nos países de origem e não deixa de surpreender em terras americanas.

Também o geógrafo Carlos Teixeira (2009) refere que, no Canadá, após o reagrupamento familiar do fim dos anos 1950, as comunidades portuguesas começam a estruturar-se no princípio dos anos 1960. Em meados dessa década já há comércio, agências de viagens, mercearias; emerge o núcleo de igrejas que difunde a sua mensagem em língua portuguesa; surgem os primeiros clubes e associações, dando-se assim início a uma comunidade. Formam-se comunidades portuguesas muito bem organizadas onde todos os dias se ouve português, se recria Portugal nos Little Portugal, pondo-se de pé muitas igrejas e clubes/associações, comércios dos mais variados, jornais e estações de rádio não se sentindo diferenças entre a Little Portugal ${ }^{2}$ (Mapa 1) em Toronto ou em Montreal.

Mapa 1: Localização do bairro português de Little Portugal (Toronto - Canadá)

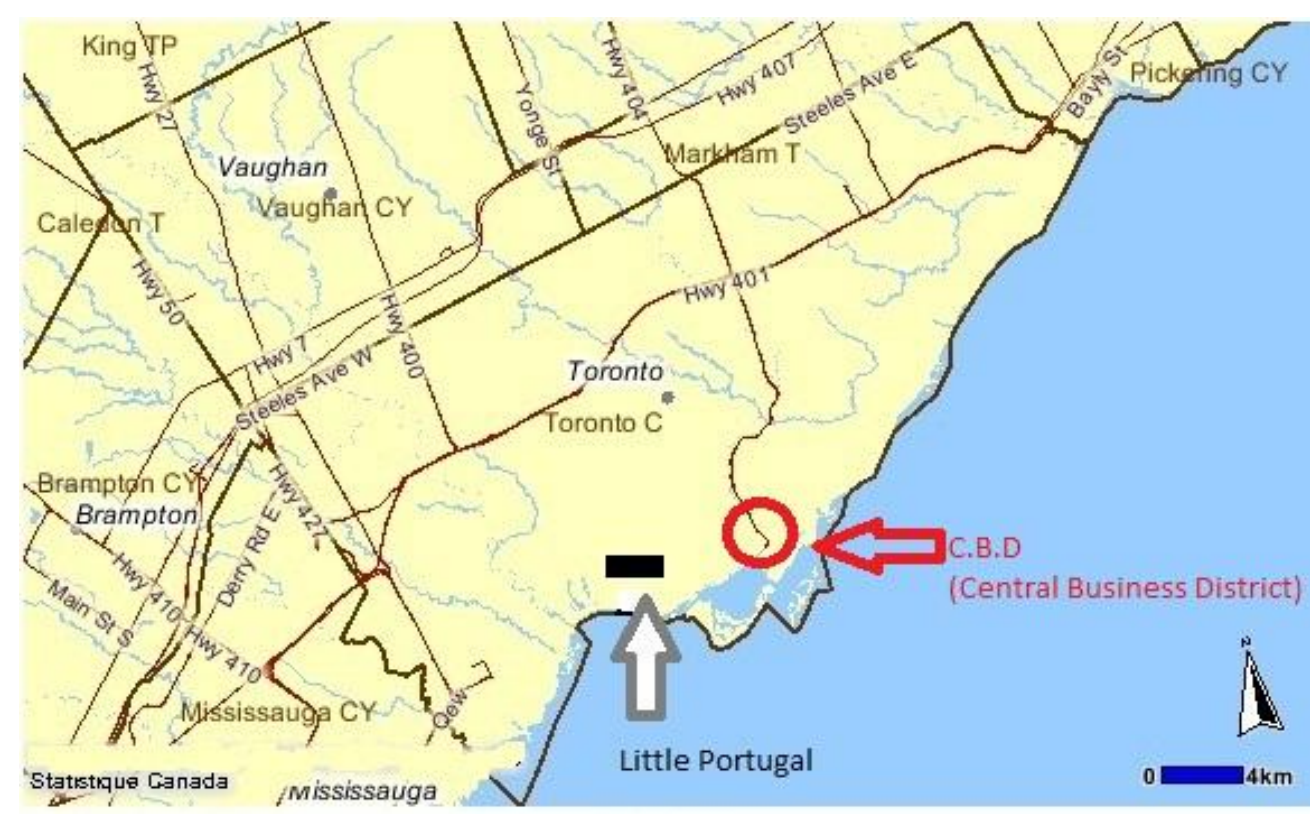

Fonte: Statistique Canada, tratamento do autor.

\footnotetext{
2 Segundo os censos canadianos, em 2001 viviam cerca de 358000 portugueses no Canadá. A área de Toronto registava os efetivos lusos mais numerosos no país (171 545), a cidade de Toronto (96 815) e o núcleo histórico da implantação lusa na zona ocidental de Toronto (Little Portugal) cerca de 12000 (Teixeira, 2007). Os dados do recenseamento de 2006 (Statistique Canada) apontam para 150398 residentes no Canadá naturais de Portugal.
} 
Se atendermos à perspetiva deste geógrafo, a génese da comunidade portuguesa no Canadá só aconteceu quando, na prática, se desenvolveu um conjunto de iniciativas que perpetuam as tradições culturais do país de origem.

Na região de Montreal, Gilles Lavigne (1995) descreve que a ocupação territorial pelos imigrantes portugueses do bairro Saint Louis, que estava em vias de ser abandonado nos anos 60, afirmou-se como Little Portugal à medida que os portugueses se concentraram, sedentarizaram e lançaram bases comunitárias. Segundo estudos efetuados por este autor, e alguns em colaboração com Carlos Teixeira, pôde-se aferir que, nas primeiras três décadas da sua implantação no Canadá, a comunidade portuguesa sofreu um processo de concentração residencial seguida de um fenómeno de desconcentração em que a mobilidade residencial da comunidade portuguesa nesta região se tornou mais facilitada graças às redes comunitárias de familiares e de amigos bem como pelas agências imobiliárias étnicas (Teixeira, 2006:129). Carlos Teixeira demonstrou como as relações étnicas ajudam na procura de emprego ou de casa nas regiões de Montreal ou de Mississauga em Toronto. Em 2007, este investigador conclui que, nos últimos anos, o bairro português de Toronto tinha passado por um processo de transição que se devia principalmente a três tendências; a primeira corresponde à movimentação de muitos portugueses do centro da cidade para os subúrbios onde encontram casas mais amplas, mais baratas e mais espaços verdes; a segunda tem a ver com a rede de profissionais que procura casas velhas próximas do núcleo central, e a terceira prende-se com a chegada de imigrantes e refugiados da diáspora portuguesa (inclui também brasileiros e pessoas das antigas colónias portuguesas). Trata-se de um exemplo de apropriação espacial em contexto imigratório em que o espaço é moldado em função das características culturais do grupo étnico que o ocupa. Teixeira percebe que o bairro português de Toronto é um espaço em transição, muitos portugueses vão para os subúrbios e o seu lugar nos bairros centrais é substituído por outras comunidades portadoras de novas dinâmicas. Também aqui é visível, tal como sucede na Europa, o fenómeno de concentração e de desconcentração residencial dos imigrantes lusos nas áreas urbanas. 
Na Europa e particularmente em França alguns estudos do domínio da Geografia analisaram a implantação territorial dos portugueses no meio rural e em áreas urbanas.

Os geógrafos Michel Drain (1968:96-97) e Michel Poinard (1972:47) referem que, em França, a habitação dos trabalhadores portugueses e espanhóis é frequentemente relacionada com o trabalho que desempenham. Numa primeira fase da chegada, os trabalhadores portugueses da construção civil vivem preferencialmente em barracas temporárias que acompanham os locais das obras.

Na década de 60 do século $X X$, os trabalhadores portugueses viviam em habitações precárias ou nos bairros de lata em detrimento dos foyers (centro de acolhimento para imigrantes) devido às regras rígidas aí vigentes. O período de 1962 a 1966 é marcado pela visibilidade dos bairros de lata onde chegaram a viver cerca de 15000 portugueses nos arredores de Paris em Champigny. Todavia, estes bairros nunca constituíram o tipo de residência predominante dos imigrantes lusos durante os anos sessenta e setenta (menos de 20\% dos portugueses chegaram a viver nestes espaços). A partir de 1975 assiste-se a uma concentração magrebina nos bairros HLM (habitation à loyer modéré - habitação Social) e simultaneamente a comunidade portuguesa conhece uma maior difusão em termos residenciais em velhos edifícios, em vivendas renovadas ou em apartamentos como porteiros em Paris e noutras cidades do país (Blanc-Chaléard, 2006).

Em França, o sociólogo Jacques Barou (2000) descreve-nos um dos numerosos exemplos de processo de implantação dos portugueses em meio rural nas várias aldeias vinícolas, que contribuíram para a revitalização de espaços rurais prometidos, em certos casos, a um despovoamento anunciado ou então orientáveis para um processo de estandardização urbana como nos arredores de Clermont-Ferrand. Na periferia desta cidade, que parecia na década 60 votada a uma urbanização estandardizada de tipo loteamento e assim perder a sua identidade rural, uma população migrante fez deste local o seu enraizamento na sociedade francesa e a principal referência memorial de uma aventura começada 40 anos antes. Os portugueses começaram por alugar ou comprar as casas do centro das aldeias e restauraram-nas sem todavia transferirem um modo de vida deixado em Portugal ou 
levarem uma vida comunitária fechada sobre si própria. As famílias reencontraram aqui uma realidade rural que tinham deixado, fazendo dessa localidade o seu património reapropriado nas dimensões tanto material como simbólica (Barou, 2000:141).

Também na região de Lyon, Poinard (1972:52-57) tinha descrito um processo semelhante de implantação dos portugueses. Este investigador constatara uma dupla orientação na implantação progressiva dos portugueses neste território; por um lado substituem os imigrantes antigos nos bairros centrais mais degradados e, por outro lado, sob o efeito da pressão demográfica e da remodelação urbana que expulsa os pobres, os mesmos se instalam nos bairros peri-urbanos e nas freguesias rurais. Os portugueses adaptam-se bem a estes espaços periféricos porque tiram proveito de condições mais favoráveis, como acontece com espaços libertados pelo êxodo rural e antigos edifícios industriais desafectados, e assim dispõem de alojamentos mais amplos do que na cidade sendo eles próprios capazes de efetuar as transformações necessárias. Todavia, em França, a implantação da comunidade lusa em meio rural concerne apenas uma ínfima parte desta comunidade que, maioritariamente, passou a viver em meio urbano. Muitas das freguesias rurais das grandes cidades francesas onde a comunidade portuguesa se implantara passaram progressivamente por um processo de rurbanização característico das últimas décadas. Nos últimos anos, a promoção e a integração socioeconómica dos imigrantes, o apoio das redes familiares e comunitárias, o recurso à autoconstrução e as práticas transnacionais de materiais e equipamentos para a habitação (adquiridos diretamente em Portugal a custo mais reduzido) têm explicado o acesso à habitação individual bem como um movimento centrífugo de maior dispersão territorial na periferia das grandes cidades (Mapa 2).

Um inquérito realizado à comunidade portuguesa de Lyon (Diogo, 2012) revelou que cerca de $37 \%$ dos inquiridos são proprietários de habitação (61,8\% possuem uma vivenda), sendo que $32 \%$ dos portugueses e lusodescendentes responderam ter recorrido à rede comunitária lusa para realizar trabalhos ou construir as suas habitações. 
O benefício económico e o sentimento de entreajuda explicam, em grande parte, 0 recurso às redes comunitárias. Os custos de realização de trabalhos podem ser revistos em baixa se tivermos também em conta as práticas informais de contratação.

Mapa 2: Implantação territorial dos portugueses na área metropolitana de Lyon (França).

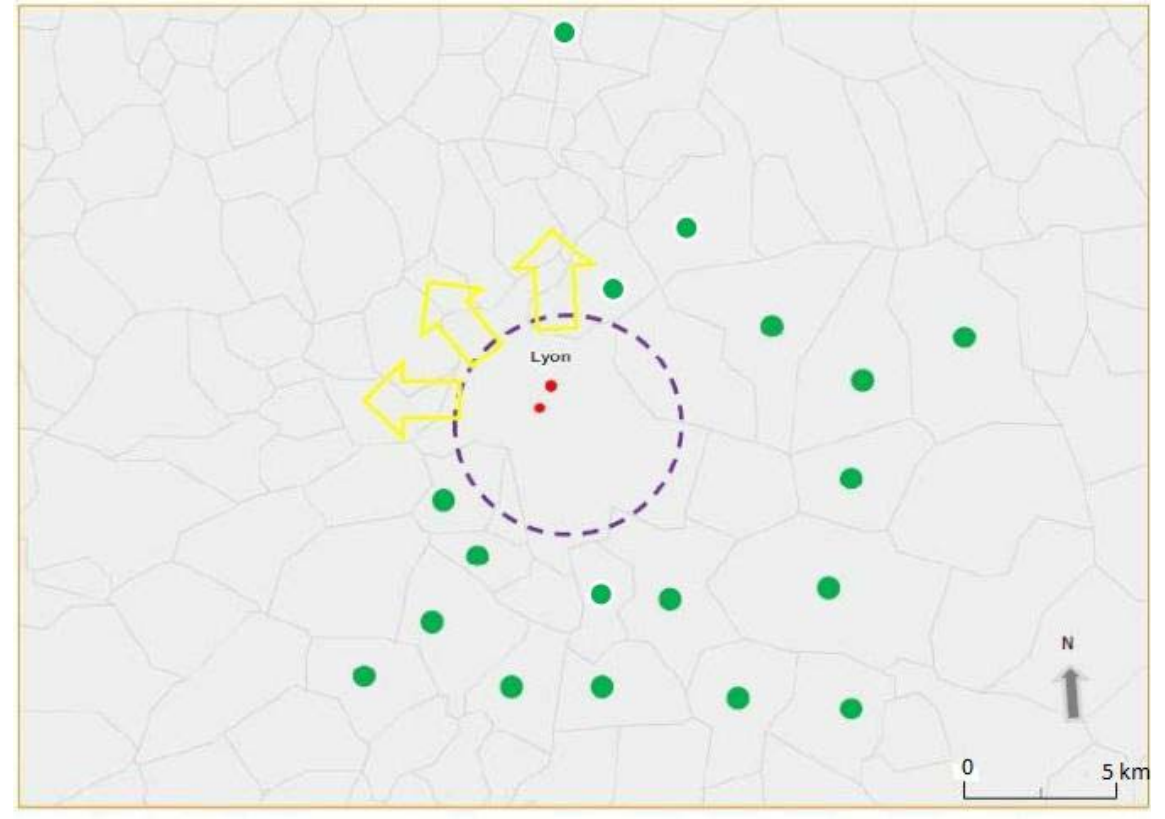

Legenda:

Implantação nas freguesias rurais ou semi-rurais (década de 1960-1970).

Implantação provisória em bairros centrais degradados (década de 1960-1970).

$1-$

Implantação nas freguesias centrais e periféricas (década de 1970 aos nossos dias).

Recentes tendências centrífugas para áreas mais valorizadas (habitação unifamiliar).

Fonte: Poinard (1972); INSEE (2000); Diogo (2012); tratamento do autor.

\section{Paisagens culturais}

Como vimos, os processos de implantação territorial dos emigrantes lusos nestes dois países efetuou-se espacialmente, numa primeira fase, por movimentos do tipo centrípeto e posteriormente centrífugo.

A escolha do local de implantação bem como a implantação também refletem opções culturais. Nesse sentido foi possível observar em França algumas características da apropriação espacial dos portugueses em meio rural, o reencontro com a ruralidade 
que tinham deixado em Portugal e a reapropriação de um património com as suas dimensões material e simbólica.

Outros investigadores como Rocha Trindade também estudaram, a partir de vários exemplos migratórios, as relações existentes entre as áreas de partida e as áreas de acolhimento dos emigrantes. Rocha Trindade (1976: 996) assinala que há uma espécie de limiar crítico, a partir do qual se criam condições para a formação de um grupo uma subcomunidade - que se estrutura socialmente com base no modelo cultural de origem. Procura-se continuar a respirar o ambiente português e, por isso, tenta-se prolongar o país através da transplantação de traços culturais de natureza material e espiritual.

Podemos prolongar Portugal e vivenciá-lo de inúmeras formas. Uma delas consiste em procurar pontos de identificação nas áreas de acolhimento, nomeadamente nos aspetos arquitetónico e paisagístico que lembram ou se assemelham com a terra de origem para aí nos fixarmos.

Neste sentido aponta a investigação que tinha iniciado em 2000 sobre a implantação da comunidade lusa na região de $\operatorname{Lyon}^{3}$ sendo que um técnico consular nos relatara analogias paisagísticas entre a região de partida e a região de chegada em França dos imigrantes lusos: A comunidade portuguesa chegou cá, adaptou-se ao meio ambiente, meio social e até mesmo ao meio físico, geográfico [...] escolhe locais que mais se assemelham com o seu ponto de origem [...] existe aqui muito perto uma grande comunidade da região de Leiria que escolheu uma zona que é muito semelhante às pradarias, chamamos-Ihe assim, daquela região de Leiria e que corresponde à zona de Cremieux, Mezieux [...] uma zona que até tem um castelo medieval parecido com aquele que D. Dinis conquistou aos Mouros em Leiria. Portanto, a comunidade procura locais mais ou menos semelhantes aos de origem e adapta-se.

Algumas investigações demonstraram as dificuldades em encontrar algum estilo arquitetónico de influência lusa reproduzido no território de acolhimento em França. Segundo Castro (2001) os constrangimentos legislativos franceses funcionam como um

\footnotetext{
${ }^{3}$ C. Ferreira in H. Diogo (2001) A comunidade portuguesa na região Rhône-Alpes numa perspectiva geográfica, económica e sociocultural, Dissertação de Mestrado em Relações Interculturais, U. Aberta, Porto.
} 
freio na intervenção exterior das habitações, levando a que as intervenções dos imigrantes em França se centrem sobretudo na esfera interior e privada.

Se efetivamente é nos difícil termos uma perceção da existência de influências culturais lusas nas fachadas das habitações, os estudos que realizamos nos finais de $2010^{4}$ na região de Lyon, demonstram, no entanto, a existência inequívoca de práticas transnacionais de materiais da construção civil como rochas ornamentais graníticas, mármores, azulejos e caixilharia, entre muitos outros. Os imigrantes proprietários ou mesmo locatários procedem do mesmo modo para mobilar a sua habitação (móveis de casa de banho, cozinha, sala e quartos por exemplo). A compra destes materiais obedece a vários critérios: um critério cultural, uma vez que os materiais continuam a integrar a arquitetura portuguesa, tendo por isso algum valor afetivo; um critério económico porque são obtidos a menor custo e um critério de possível ostentação/distinção. $O$ inquérito permitiu constatar que cerca de $1 / 5$ dos inquiridos já trouxe materiais de Portugal para a sua habitação em França. Os números são ainda mais expressivos quando se trata de imigrantes que são proprietários da sua habitação $(71,2 \%)$ e que vivem maioritariamente numa vivenda $(61,8 \%)$. Os materiais trazidos de Portugal são diversos, mas destacam-se para o apetrechamento da habitação os móveis de sala (16\%), de quarto (14\%) de cozinha (12\%) e como materiais da construção civil, granitos, azulejos e madeiras.

Estes resultados confirmam o papel das influências culturais no processo de construção da territorialidade imigrante lusa neste país, embora o contributo para a construção de paisagens culturais não se resuma apenas ao setor da habitação, sendo, por isso, imprescindível incluirmos na sua análise outros referenciais territoriais que incluem as atividades étnicas do foro económico ou cultural.

Na Europa, como já foi sublinhado, não se vislumbra o mesmo grau de concentração de atividades étnicas lusas como sucede por exemplo na América do norte (Mapa 3). Elas aparecem por vezes em pequenos núcleos nos centros das grandes metrópoles mas na sua maioria encontram-se disseminadas na paisagem urbana. Esta distribuição permite uma multipolarização do espaço onde se encontram e, deste modo,

\footnotetext{
${ }^{4}$ Ver resultados do questionário (pp. 306-309) e entrevistas (pp. 184-185) in H. Diogo (2012) Multiculturalismo: identidade e territorialidade na comunidade portuguesa de Lyon (França), Tese de Doutoramento, U. Porto.
} 
contribuem para um maior equilíbrio espacial em termos de distribuição das diferentes atividades.

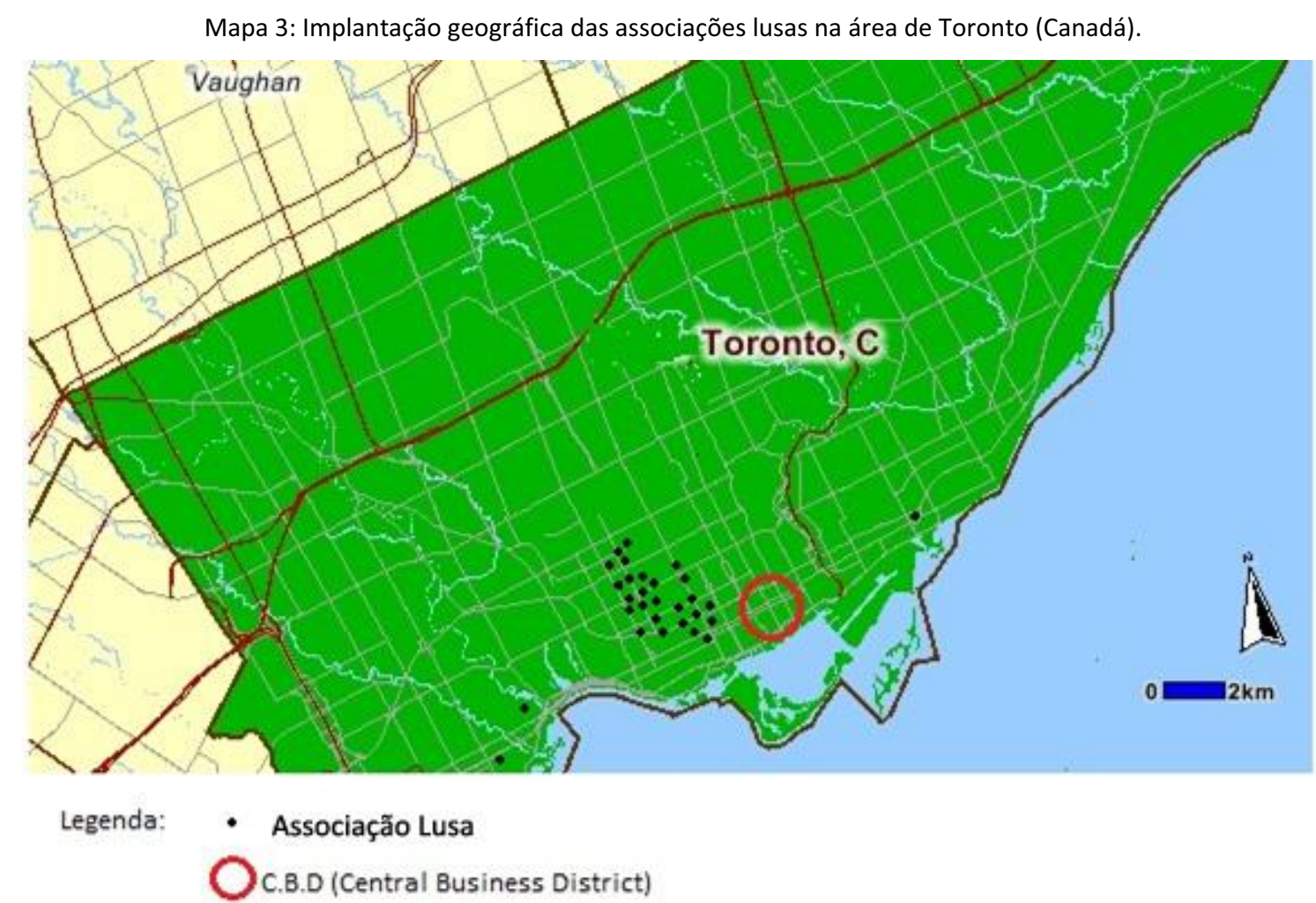

Fonte: The Portuguese Canadians Clubs and Societies Page, tratamento do autor.

As associações culturais lusas em França acompanharam a evolução do próprio fenómeno imigratório português no país passando de algumas dezenas no início da década de 1970 a cerca de 1000 em 2011 (DGACCP, 2011). Constituem bons exemplos de territorialidade onde se respira Portugal com toda a simbologia cultural que elas apresentam ao desenvolver no seu seio atividades recreativas, desportivas, educativas e culturais de todo o género.

$\mathrm{Na}$ área de Lyon registam-se aproximadamente 40 associações culturais e desportivas lusas. Nas últimas duas décadas assistimos a uma redução do número de associações nas zonas centrais e a uma prevalência das mesmas nas zonas periféricas mais próximas bem como em núcleos urbanos circundantes de menor dimensão onde existem importantes comunidades lusas (Mapa 4). O desenvolvimento dos espaços associativos em zonas centrais é travado pelos preços elevados praticados em termos de arrendamento imobiliário. A venda de produtos, nomeadamente de bebidas, permite às associações resolver o problema crónico de autofinanciamento com que se debatem. A dificuldade em ter um local próprio é notória, ainda mais que, para cerca 
de metade das associações, os espaços são apenas disponibilizados pelas autarquias aos fins de semana.

Nos espaços urbanos mais periféricos, o custo de arrendamento é menor e as ligações ao poder local (câmaras municipais), que disponibiliza locais para as associações desenvolverem as suas atividades, constitui uma solução que também envolve objetivos políticos assumidos por parte de alguns presidentes associativos e dirigentes autárquicos.

Mapa 4: Implantação geográfica das associações lusas na área de Lyon (França).

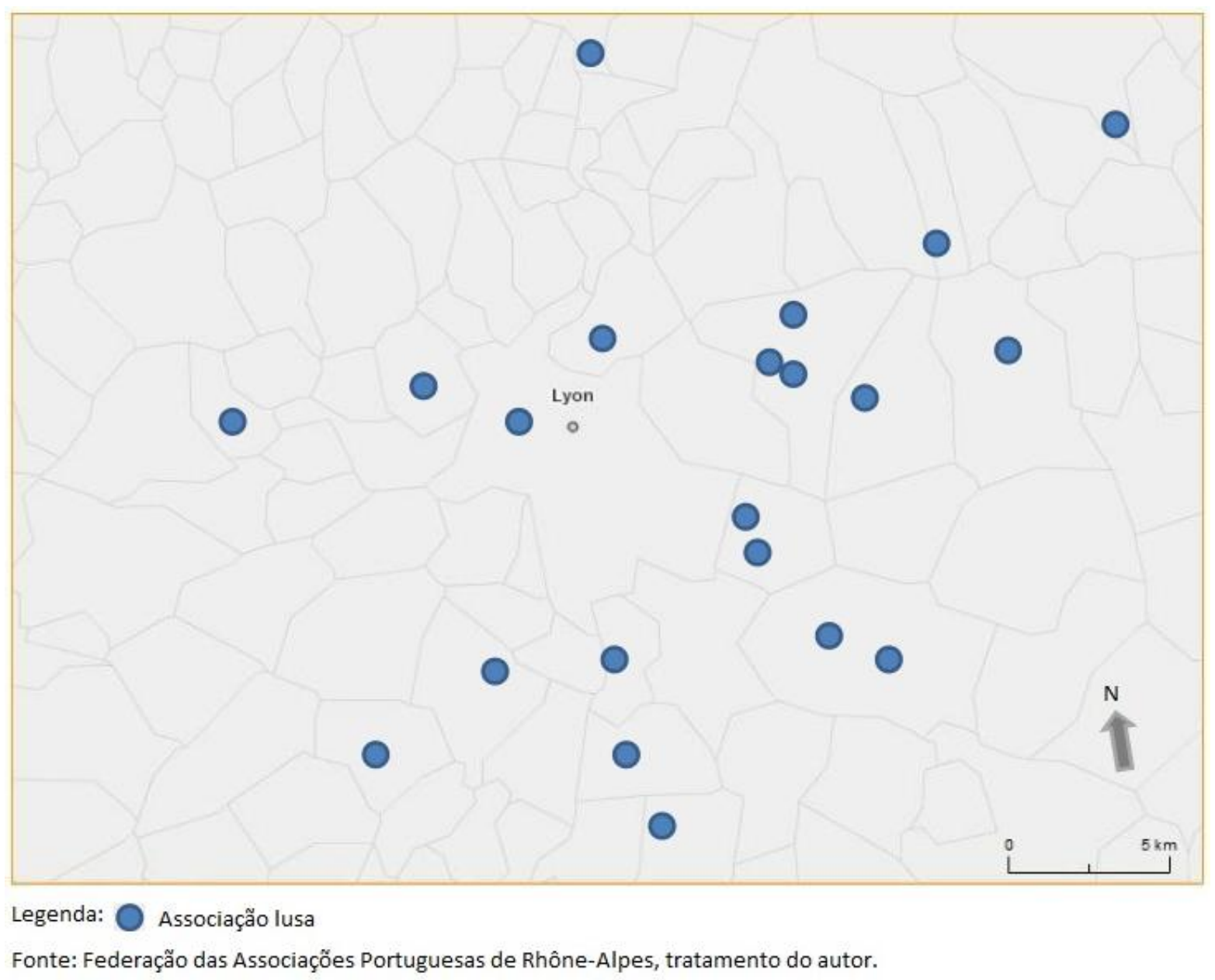



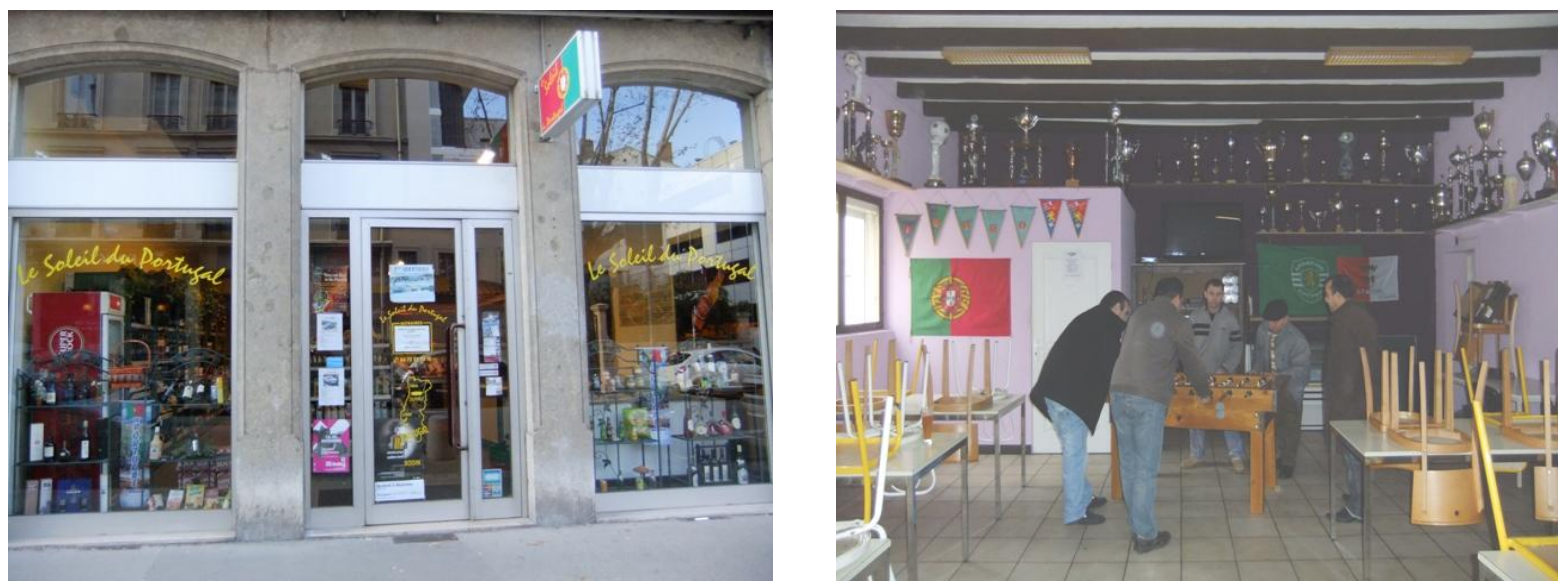

\section{Conclusões}

Como vimos existem semelhanças e diferenças nos processos de fixação territorial da comunidade lusa nos dois lados do Atlântico.

No Canadá a implantação dos portugueses em Toronto e em Montreal permitiu uma redinamização dos núcleos centrais onde se desenvolveram bairros como Little Portugal (com forte concentração populacional lusa e respetivas atividades étnicas), formam ilhas culturais na sociedade canadiana.

Na Europa, e particularmente em França a implantação dos portugueses permitiu uma redinamização das vilas e das aldeias em meio rural ou semirrural próximas dos grandes núcleos urbanos onde se instalaram. Numa primeira fase, os imigrantes lusos ocuparam diferentemente o espaço em bairros de lata na região parisiense ou ainda em bairros degradados centrais como em Lyon de modo provisório porque os mesmos se encontravam em processo de renovação urbana.

Posteriormente, quer no Canadá, quer em França a melhoria socioeconómica dos imigrantes lusos ao longo das últimas décadas e o apoio de redes familiares e comunitárias têm contribuído para uma mobilidade residencial para áreas mais valorizadas na periferia das cidades.

A investigação empírica na região de Lyon demonstrou que as práticas transnacionais de materiais da construção civil e de materiais diversos para a habitação têm uma 
influência cultural na construção da habitação dos imigrantes lusos, embora mais restringida ao espaço interior das habitações. Neste país, as atividades culturais lusas, à semelhança do padrão de distribuição populacional, encontram-se também mais homogeneamente dispersas pelo território, como o comprova a dispersão do movimento associativo na paisagem local. Contrariamente ao Canadá, na região de Lyon, a menor concentração espacial de locais étnicos assemelha-se mais a ilhéus culturais na sociedade autóctone.

Apesar de processos de implantação espacial, por vezes distintos nos dois continentes, a territorialidade das comunidades lusas tem-se construído continuamente com base em relações culturais mantidas com o país de origem, expressando a essência da portugalidade e contribuindo, deste modo, para a manutenção da identidade lusa nas sociedades de acolhimento.

\section{Referências bibliográficas}

Barou, J. (2000). Immigrés portugais dans la péripherie de Clermont-Ferrand: refaire la campagne a deux pas de la ville. Campagnes de tous nos desirs, Rautenberg et al, Paris, Editions de la Maison des Sciences de l'Homme: 141-151.

Bonnemaison, Joel (2000). La géographie culturelle. Éditions du CTHS, Paris, 152 p.

Castro, A. (2001). Une "esthétique interculturelle": les constructions des immigrés portugais. Construire L'interculturel. Villanova et al., Paris, L'Harmattan: 327-342.

Blanc-Chaléard, M.C (2006). Les immigrés et le logement en France depuis le XIXe siècle - Une histoire paradoxale. Revue Hommes et migrations (1264): 20-34.

Cordeiro, A. (1999) Dans quinze ans, Qu'adviendra-t-il de l'identité des Portugais de France?. Revues-Plurielles, Latitudes (5): 3-6.

Claval, P. (1995). Géographie culturelle. Natahan, Paris, 384 p.

Claval, Paul (2008). La géographie culturelle dans les pays anglophones. Annales de Géographie, (660-661):8-26. 
Diogo, H. (2001). A comunidade portuguesa na região Rhône-Alpes numa perspectiva geográfica, económica e sociocultural. Mestrado, Universidade Aberta.

Diogo, H. (2012). Multiculturalismo: identidade e territorialidade na comunidade portuguesa de Lyon (França). Doutoramento, Universidade do Porto.

Di Meo, G. (1998). Géographie sociale et territories. Paris, Nathan, 320 p.

Direç̧ão Geral Assuntos Consulares (2011). Registos Consulares de Portugal em França. Lisboa.

Drain, M. (1968). Les migrations de travailleurs espagnols et portugais en Europe, d'après des ouvrages récents. Annales de Géographie (419): 96-98.

Dufoix, S. (2003). Les diasporas, Paris, Que sais-je? P.U.F, 127 p.

George, P. (1976). Les migrations internationales. Paris, PUF, 230 p.

Haesbaert, R. (2004). Dos múltiplos territórios à multiterritorialidade. [Acedido em 07 de Novembro de 2010], www.6.ufrgs.br/petgea/Artigo/rh.pdf

INSEE (2000). Recensement de la population, Rhône-Alpes, Paris.

Lavigne, G. et al. (1995). L'ethnicisation de l'établissement humain en Amérique du Nord: l'exemple du quartier portugais à Montréal. Cahiers de géographie du Québec 39 (108): 417-443.

Poinard, M. (1972). Les Portugais dans le département du Rhône entre 1960 et 1970. Revue de géographie de Lyon 47 (1): 35-58.

Rocha Trindade, M. B. (1976). “Comunidades migrantes em situações duplas: análise de três casos de emigrações espalhadas pelos EUA, pelo Brasil e pela França." Análise Social 12 (48): 983-997.

Sack, R. (1986). Human territoriality - its theory and history - Cambridge, Cambridge University Press, 259 p.

Statistique Canada (2012). GéoRecherche. Recensement de 2011. No 92-142-XWF au catalogue de Statistique Canada. Ottawa (Ontario).

Teixeira, C. (2006). A comparative study of Portuguese homebuyers's suburbanization in the Toronto and Montreal areas. Espaces et Societés 2006 (1): 121-135. 
Teixeira, C. (2007). Toronto's Little Portugal - A Neighbourhood in Transition. Research

Bulletin (35), [Acedido em 12 de Dezembro de 2010]

www.urbancenter.utoronto.ca/redirects/rb35.html

Teixeira, C; Rosa, V. (2009). The portuguese in Canada, second edition. Toronto, University of Toronto Press, $299 \mathrm{p}$. 